\title{
ESTÁDIOS DE MATURAÇÃO DE PÊSSEGOS 'AURORA-1' PARA O PROCESSAMENTO MÍNIMO'
}

\author{
RAMILO NOGUEIRA MARTINS², BEN-HUR MATTIUZ², LEANDRA OLIVEIRA SANTOS², \\ ELLEN TOEWS DOLL HOJO², CLAUDIA FABRINO MACHADO MATTIUZ ${ }^{3}$
}

RESUMO- O experimento teve como finalidade verificar o efeito do estádio de maturação na qualidade de pêssegos minimamente processados. Utilizaram-se frutos em dois estádios de maturação: "de vez", correspondente à coloração de fundo verde-amarelada; e "maduro", que corresponde à cor de fundo totalmente amarelado. O processamento mínimo consistiu na lavagem, sanitização, descasque enzimático, corte longitudinal e retirada do caroço das frutas. As metades obtidas foram imersas em água clorada a 10 $\mathrm{mg} \mathrm{L}^{-1}$ de água e deixadas em repouso para escorrer o excesso de líquido. Posteriormente, procedeu-se ao acondicionamento das metades em contentores de tereftalato de polietileno (PET) transparente e com tampa, e ao armazenamento a $3 \pm 2{ }^{\circ} \mathrm{C}$ e UR $=65 \%$, por 12 dias, com avaliações a cada três dias. As variáveis avaliadas foram aparência, perda de massa fresca, firmeza, sólidos solúveis, teores de acidez titulável, açúcares solúveis e redutores, ácido ascórbico, pectina total e solúvel, coloração e atividade da polifenoloxidase. O armazenamento dos produtos minimamente processados dos pêssegos 'Aurora-1' colhidos maduros foi limitado, principalmente pela perda de frescor e de firmeza, e por apresentarem aparência mais escura e menor teores de açúcares redutores e de ácido ascórbico. Pêssegos 'Aurora-1', colhidos no estádio de maturação "de vez", apresentaram melhor qualidade e maior durabilidade de seus produtos minimamente processados. Termos para indexação: Prumus persica, ponto de colheita, colheita, processamento.

\section{MATURITY STAGES OF PEACHES ‘AURORA-1' FOR THE MINIMUM PROCESSING}

\begin{abstract}
The experiment aimed to verify the effect of maturation stage on the quality of minimally processed peaches. Fruits were used in two stages of maturity, "on time" corresponding to the background color yellow-green, and "mature", which corresponds completely to the background color yellow. The minimum process consisted of washing, sanitizing, enzyme peel, cut lengthwise and removed the stone fruits. Halves obtained were immersed in water chlorinated to $10 \mathrm{mg} \mathrm{L}^{-1}$ of water and left on standing to drain the excess liquid. Afterwards, it was proceeded the packaging of the halves in containers of polyethylene terephthalate (PET) and with transparent lid, and the storage at $3 \pm 2{ }^{\circ} \mathrm{C}$ and $\mathrm{RH}=65 \%$ for 12 days, with assessments every three days. The variables evaluated were appearance, weight loss, firmness, soluble solids, titratable acidity, soluble and reduced sugars, ascorbic acid, total and soluble pectin, coloring and activity of polyphenoloxidase. The storage of minimally processed peaches 'Aurora-1' mature harvested was limited mainly by the loss of freshness and firmness, and because they have darker appearance, and lower levels of reduced sugars and ascorbic acid. Peaches 'Aurora-1', harvested at the maturity stage "on time", had better quality and longer duration of their minimally processed products.
\end{abstract}

Index terms: Prumus persica, harvest point, harvest, processing.

\footnotetext{
'(Trabalho 191-12). Recebido em: 18-06-2012. Aceito para publicação em: 10-05-2013.

${ }^{2}$ Faculdade de Ciências Agrárias e Veterinárias, UNESP - Univ Estadual Paulista, Câmpus de Jaboticabal, Departamento de Tecnologia. Via de Acesso Prof. Paulo Donato Castellane, s/n. CEP: 14.884-900. Jaboticabal-SP. *Autor para correspondência. E-mails: martinsnr@hotmail.com; benhur@fcav.unesp.br; leandraoli@yahoo.com.br; ellendollhojo@yahoo.com.br ${ }^{3}$ Centro Universitário Moura Lacerda. Unidade II - Campus Ribeirão Preto. Av. Dr. Oscar de Moura Lacerda, 1520. CEP: $14076-510$. Ribeirão Preto-SP. E-mail: cmattiuz@gmail.com
} 


\section{INTRODUÇÃO}

Os produtos minimamente processados tornam-se cada vez mais populares como itens de conveniência, pela praticidade e qualidade oferecida por essa operação (COUTO, 2004). Entretanto, o desafio para a inclusão das frutas no mercado de produtos minimamente processados está relacionado à limitada vida útil dos mesmos, devido principalmente, ao excessivo amolecimento e escurecimento da superfície cortada (GORNY et al., 2002).

A comercialização de pêssegos minimamente processados tem sido limitada pelas respostas fisiológicas imediatas dos tecidos aos ferimentos, com escurecimento enzimático, principalmente, pelas enzimas polifenoloxidase e peroxidase, colapso na cavidade do caroço e perda de firmeza (GORNY et al., 1998). De acordo com Remorin (2008), a qualidade do pêssego depende fortemente da época de colheita, com o estádio de maturação determinado com base em parâmetros químicos e físicos.

A colheita dos pêssegos é realizada, na maioria dos casos, em estádios iniciais de maturação, com objetivo de prolongar o período de armazenamento. (TECCHIO, et al., 2011), Em consequência, a qualidade sensorial dos frutos é baixa quando estas amadurecem e a suscetibilidade a distúrbios fisiológicos e danos mecânicos aumenta (FERRER et al., 2005). Por outro lado, colher os frutos totalmente maduros resulta em pêssegos com elevada qualidade, porém com baixo potencial de armazenamento, sendo mais apropriados ao consumo imediato (ROMBALDI et al., 2002).

Diante do exposto, o presente trabalho teve como finalidade verificar o efeito do estádio de maturação na qualidade de pêssegos minimamente processados.

\section{MATERIAL E MÉTODOS}

Pêssegos da variedade Aurora 1 foram adquiridos nos meses de outubro e novembro de 2007, em pomar comercial localizado no município de Taiúva-SP, distante cerca de $30 \mathrm{~km}$ do município de Jaboticabal-SP. Os frutos foram colhidos em dois estádios de maturação: "de vez", correspondente à coloração de fundo verde-amarelada; e "maduro", que corresponde à cor de fundo totalmente amarelado.

Visando à caracterização inicial dos frutos, foi realizada a análise de uma amostra no dia da colheita (Tabela 1).

Depois de colhidos, os frutos foram acondicionados em caixas plásticas revestidas com plástico tipo "bolha" e transportados para o Laboratório, onde foram selecionados de acordo com a uniformidade da cor, o tamanho e a ausência de injúrias mecânicas e fisiológicas. Após a seleção, os frutos foram lavados com detergente neutro biodegradável sob água corrente e higienizada por imersão, em solução de dicloro s. triazinatriona sódica di-hidratada (Sumaveg®) a $200 \mathrm{mg}$ de cloro livre $\mathrm{L}^{-1}$, por 15 minutos e deixado escorrer o excedente de água livre. Em seguida, os pêssegos foram levados à câmara fria previamente sanitizada e a $12{ }^{\circ} \mathrm{C} \pm 2{ }^{\circ} \mathrm{C}$, permanecendo por 12 horas até o processamento.

O processamento consistiu em descasque enzimático, imergindo-se os frutos em solução do produto comercial Peelzym ${ }^{\circledR}$ (Novozymes Latin América Ltda), por 60 minutos, conforme o indicado para pêssegos. Após a imersão, os frutos foram lavados com água destilada para a retirada da casca. Em seguida, fez-se um corte longitudinal, seguindo a linha de sutura do fruto, e utilizando-se de uma colher apropriada, retirou-se o caroço. As metades obtidas foram enxaguadas em solução de água clorada a $10 \mathrm{mg}$ de cloro ativo $\mathrm{L}^{-1}$ e deixados em repouso para escorrer o excesso de líquido. Posteriormente, procedeu-se ao acondicionamento em contentores de tereftalato de polietileno (PET) transparente e com tampa, com capacidade de $500 \mathrm{~mL}$ (Neoform ${ }^{\circledR}$ $\mathrm{N}-90$ ), antes de serem armazenados a $3 \pm 2{ }^{\circ} \mathrm{C}$ e $\mathrm{UR}=65 \%$, por 12 dias. Cada embalagem continha aproximadamente $200 \mathrm{~g}$ do produto.

$\mathrm{O}$ experimento foi realizado em delineamento inteiramente casualizado, em esquema fatorial $2 \times 5$, com dois estádios de maturação e cinco datas de amostragem $(0 ; 3 ; 6 ; 9$ e 12 dias). Utilizaram-se três repetições por tratamento, tendo cada uma, aproximadamente, $200 \mathrm{~g}$ do produto.

Durante o período de armazenamento, os produtos foram avaliados a cada três dias, quanto à massa fresca: foi determinado por pesagem em balança eletrônica com capacidade para 2000 g, e precisão de $0,1 \mathrm{~g}$, sendo expressa em porcentagem. Quanto à aparência, atribuindo-se, através de escala hedônica, notas de 4 a 1, em que: 4 (ótimo) = aspecto fresco e ausência de escurecimento; 3 (bom) = aspecto fresco, porém com leve escurecimento; 2 (regular) $=$ pouco aspecto de frescor e leve escurecimento; 1 (ruim) = murchos e escurecidos. A nota 3 foi considerada o limite de aceitação comercial.

A coloração da polpa foi obtida com o uso do colorímetro Minolta Corp CR-400, sendo expressa pela luminosidade, cromaticidade e ângulo de cor. O teor de sólidos solúveis (SS) foi expresso em ${ }^{\circ}$ Brix por refratometria. $\mathrm{O}$ teor de ácido ascórbico $(\mathrm{mg}$ $100 \mathrm{~g}^{-1}$ ) foi determinado: por método titulométrico, utilizando 2,6 diclofenol indofenol (INSTITUTO 
ADOLFO LUTZ, 2008). O conteúdo de açúcares solúveis e redutores foi determinado conforme Dubois et al. (1956) e Miller (1959), respectivamente, sendo os resultados expressos em \% de glicose. A atividade da enzima polifenoloxidase foi determinada pelo método modificado de Allain et al. (1974), sendo expressa em $\mu \mathrm{mol}$ de fenol consumido $\mathrm{min}^{-1} \mathrm{~g}^{-1}$.

Os dados obtidos foram submetidos à análise de variância (ANOVA), e as médias dos estádios de maturação foram comparadas pelo teste de Tukey, a 5\% de probabilidade de erro, e as datas de amostragens foram representadas por equações de regressão.

\section{RESULTADOS E DISCUSSÃO}

Nas condições do experimento, não foi verificada diferença significativa na perda de massa fresca de pêssegos minimamente processados, nos dois estádios de maturação testados (Figura 1). A perda de massa fresca ao longo do período de armazenamento foi constante para os produtos de ambos os estádios de maturação. No último dia de análise, esta perda foi da ordem de $0,75 \%$ e $0,69 \%$ em massa, para produtos de frutos "de vez" e maduros, respectivamente. Tal perda é atribuída às reações metabólicas, como a respiração e a transpiração do produto, que reduzem a quantidade da água presente no tecido vegetal.

Com relação à aparência, os produtos minimamente processados, provenientes de frutos no estádio de maturação "de vez", mostraram-se com melhor aparência em relação aos produtos processados de frutos maduros até o nono dia de armazenamento (Figura 2A), proporcionando bom aspecto aos produtos até o sexto dia de armazenamento, com nota 3 , podendo ser recomendados para a comercialização. Possivelmente, o estádio de maturação "de vez" conferiu maior resistência aos danos ocasionados pelo processamento mínimo, garantindo produtos com melhor qualidade visual. A solubilização de substâncias pécticas é uma tendência natural durante o amadurecimento dos frutos. Estas substâncias são depositadas na parede celular, sendo responsáveis pela firmeza dos frutos. Derivam-se do ácido poligalacturônico e ocorrem na forma de pectina, protopectina, ácidos pectínicos e ácidos pécticos. As protopectinas são convertidas em pectina solúvel e causam o amaciamento nos frutos com o avanço do amadurecimento (CHITARRA; CHITARRA, 2005).

$\mathrm{Na}$ Figura 2B, é possível verificar que as fatias de pêssegos de frutos maduros apresentaram maiores teores de sólidos solúveis durante todo o período de armazenamento. Os teores médios de sólidos solúveis nas fatias de frutos maduros e "de vez" foram de $11,02^{\circ} \mathrm{Brix}$ e $10,36^{\circ} \mathrm{Brix}$, respectivamente, os quais estão acima dos obtidos por Oliveira e Cereda (2003), que trabalharam com pêssegos 'Biuti', armazenados (12 dias) sob condição ambiente, e cujos valores foram de $7,9^{\circ}$ Brix a $10,1^{\circ}$ Brix e menores que os relatados por Cunha et al. (2007) que foi de 11,8 ${ }^{\circ}$ Brix, respectivamente, para pêssegos 'Aurora-1'. Segundo Mathias et al. (2008), a escolha da cultivar e as práticas culturais adotadas na implantação e na condução do pomar influenciam na qualidade dos frutos, o que esclarece a diferença nos teores de sólidos solúveis observados entre os autores.

Verificou-se um aumento acentuado no conteúdo de açúcares solúveis durante o período de armazenamento, com valores médios que evoluíram de $12,26 \%$ para $14,05 \%$ (Figura $3 \mathrm{~A}$ ). Este aumento nos teores de açúcares solúveis tem sido atribuído à transformação das reservas acumuladas, principalmente de amido, durante o desenvolvimento dos mesmos ou pelo aumento no metabolismo desencadeado pela injúria no processamento (MATTIUZ et al., 2003). Segundo Chitarra e Chitarra (2005), os teores de açúcares em frutos climatéricos, usualmente, aumentam na ordem de $10 \%$ com o amadurecimento através de processos de biossíntese ou pela degradação de polissacarídeos.

Na Figura 3B, observa-se que houve aumento progressivo no teor de açúcares redutores ao longo do armazenamento, nos dois tratamentos, onde as metades obtidas de frutos "de vez" apresentaram as maiores médias durante todo o período de armazenamento. Estes valores reafirmam o obtido por Cunha et al. (2007), que trabalharam com pêssegos 'Aurora-1', e obtiveram médias de $1,77 \%$ de glicose para frutos "de vez" e $1,38 \%$ de glicose para frutos maduros, aos 14 dias de armazenamento refrigerado $\left(6^{\circ} \mathrm{C}\right)$.

$\mathrm{Na}$ Figura 4A, nota-se que, durante o período de armazenamento refrigerado, houve redução nos teores de ácido ascórbico nas metades de frutos "de vez" e maduro, provavelmente pelo consumo e oxidação deste ácido decorrente do estresse sofrido pelo processamento. Nota-se também que as metades obtidas de pêssegos "de vez" apresentaram teores de ácido ascórbico superiores aos de frutas maduras até o final do experimento. Transformações ocorridas durante o processo de amadurecimento nas frutas resultam de oxidações e consequente transformação do ácido ascórbico em ácido 2,3-dicetogulônico (CHITARRA; CHITARRA, 2005).

A atividade da polifenoloxidase (PPO) foi menor durante todo o armazenamento refrigerado nas metades dos pêssegos maduros e mantiveram-se constantes até o final do período. Tendência similar foi observada nos produtos dos pêssegos "de vez" (Figura 4B). Coseteng e Lee (1987) observaram, 
em maçãs, decréscimo da PPO com a progressão da maturação.

Ainda na Figura 4B, observou-se que a atividade da $\mathrm{PPO}$, nos produtos de ambos os estádios, mostrou decréscimo na atividade, no nono dia, com posterior aumento, sendo mais bem evidenciado nas fatias de pêssegos "de vez". Este fato também foi observado por Carvalho (1998), que relatou decréscimo na atividade da PPO, no décimo dia, com posterior aumento, em pêssegos 'Rio Grandense'. Segundo este autor, a atividade máxima da enzima polifenoloxidase foi detectada no período inicial de armazenamento.

Apesar do armazenamento a baixa temperatura $\left(3^{\circ} \mathrm{C}\right)$ e da proteção oferecida pela embalagem, verificou-se escurecimento nos produtos ao longo do período, para ambos os estádios de maturação
(Figura 5A). Ao mesmo tempo, o aumento na cromaticidade (Figura 5B), aliado à redução no ângulo de cor (Figura 5C), indica melhoria na cor, devido ao acúmulo de caroteoides, que levou à tonalidade amarelada mais intensa durante o armazenamento.

A redução na luminosidade, neste caso, concorda com Kasat et al. (2007), que, trabalhando com injúrias mecânicas em pêssegos 'Aurora-1', também observaram redução da luminosidade durante o armazenamento a $10{ }^{\circ} \mathrm{C} \pm 1,5^{\circ} \mathrm{C}$.

Os resultados deste experimento indicam que o armazenamento dos produtos minimamente processados dos pêssegos 'Aurora-1', colhidos maduros, foi limitado, principalmente pela perda de frescor e de firmeza, e por apresentarem aparência mais escura, e menores teores de açúcares redutores e de ácido ascórbico.

TABELA 1- Caracterização física e físico-química de pêssegos 'Aurora 1' colhidos em dois estádios de maturação.

\begin{tabular}{lcc}
\hline \multirow{2}{*}{ Parâmetro } & \multicolumn{2}{c}{ Estádio de maturação } \\
\cline { 2 - 3 } & "de vez" & maduro \\
\hline Comprimento do fruto $(\mathrm{cm})$ & $5,7 \pm 0,3$ & $6,1 \pm 0,3$ \\
Largura do fruto $(\mathrm{cm})$ & $5,1 \pm 0,4$ & $5,2 \pm 0,3$ \\
Firmeza $(\mathrm{N})$ & $33,34 \pm 1,65$ & $31,60 \pm 3,40$ \\
Sólidos solúveis $\left({ }^{\circ}\right.$ Brix) & $10,44 \pm 0,21$ & $10,78 \pm 0,52$ \\
Acidez titulável (g ácido cítrico $\left.100 \mathrm{~g}^{-1}\right)$ & $0,33 \pm 0,03$ & $0,27 \pm 0,02$ \\
Luminosidade da casca & $74,60 \pm 2,10$ & $79,85 \pm 2,43$ \\
Ângulo de cor da casca & $108,28 \pm 3,11$ & $93,36 \pm 3,40$ \\
Cromaticidade da casca & $52,60 \pm 2,05$ & $59,20 \pm 3,58$ \\
\hline
\end{tabular}

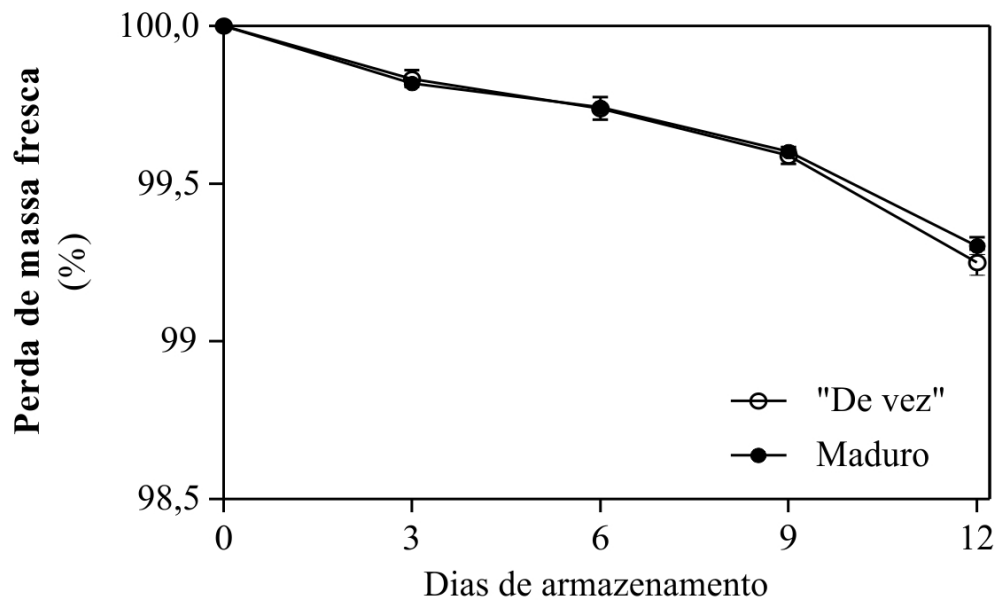

FIGURA 1- Perda acumulada de massa fresca (\%) em pêssegos 'Aurora-1' minimamente processados, em dois estádios de maturação, e armazenados a $3{ }^{\circ} \mathrm{C}$ e $65 \%$ UR. Barras verticais indicam \pm desvio-padrão da média. 


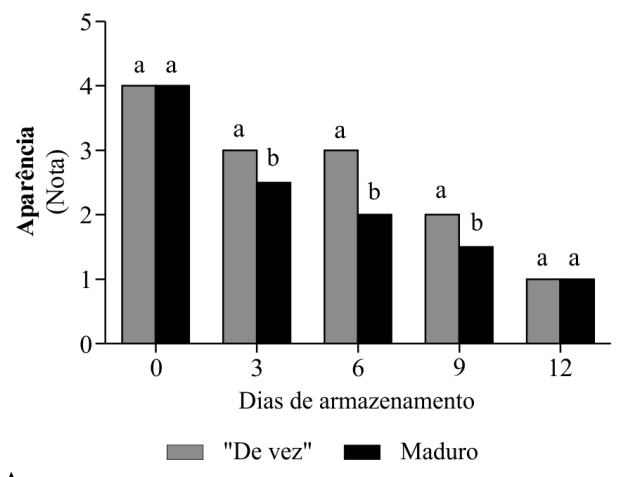

A

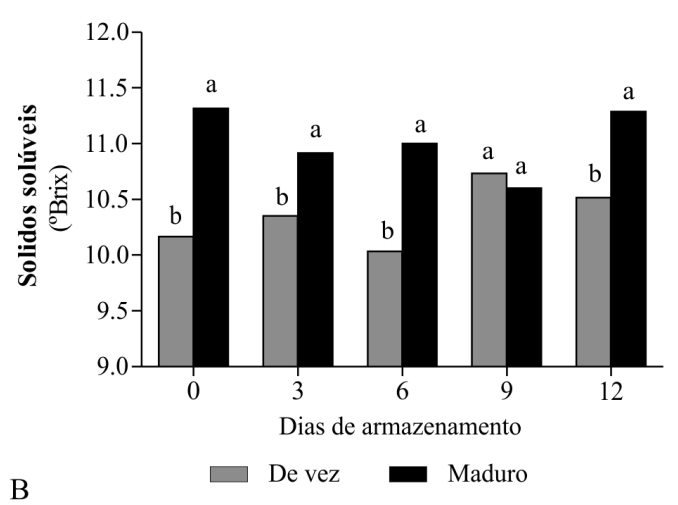

FIGURA 2- Aparência (A) e teores de sólidos solúveis ( ${ }^{\circ}$ Brix) (B) de pêssegos 'Aurora-1' submetidos ao processamento mínimo, em dois estádios de maturação, e armazenados a $3{ }^{\circ} \mathrm{C}$ e $65 \% \mathrm{UR}$. Critérios: 4 = ótimo; 3 = bom; 2 = regular, e $1=$ ruim. Médias seguidas de mesma letra dentro de cada período de armazenamento não diferem significativamente, pelo teste de Tukey $(\mathrm{P}<0,05)$.

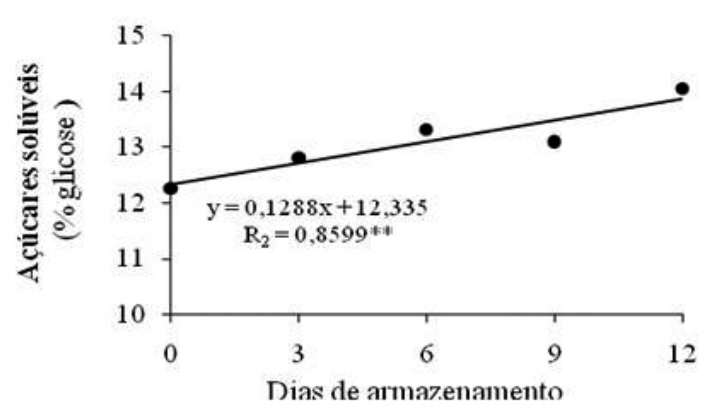

A

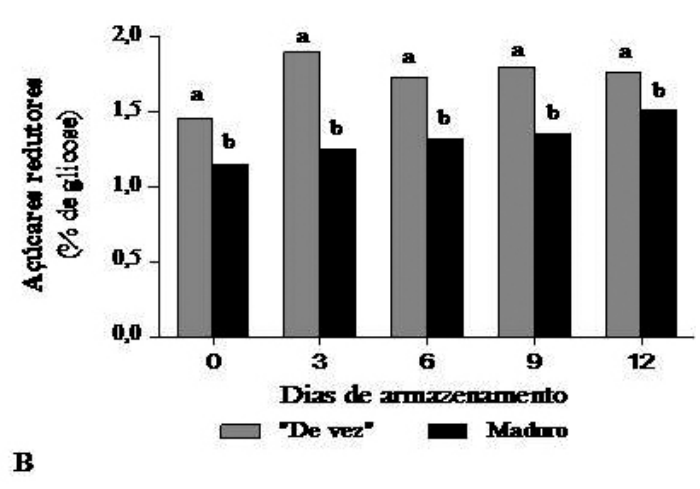

FIGURA 3- Teores de açúcares solúveis (A) e redutores (B), em \% de glicose, de pêssegos 'Aurora-1' submetidos a processamento mínimo, em dois estádios de maturação, e armazenados a $3{ }^{\circ} \mathrm{C}$ e $65 \%$ UR. Em cada dia, as letras diferentes indicam diferenças estatísticas entre os resultados, pelo teste de Tukey $(\mathrm{P}<0,05)$.
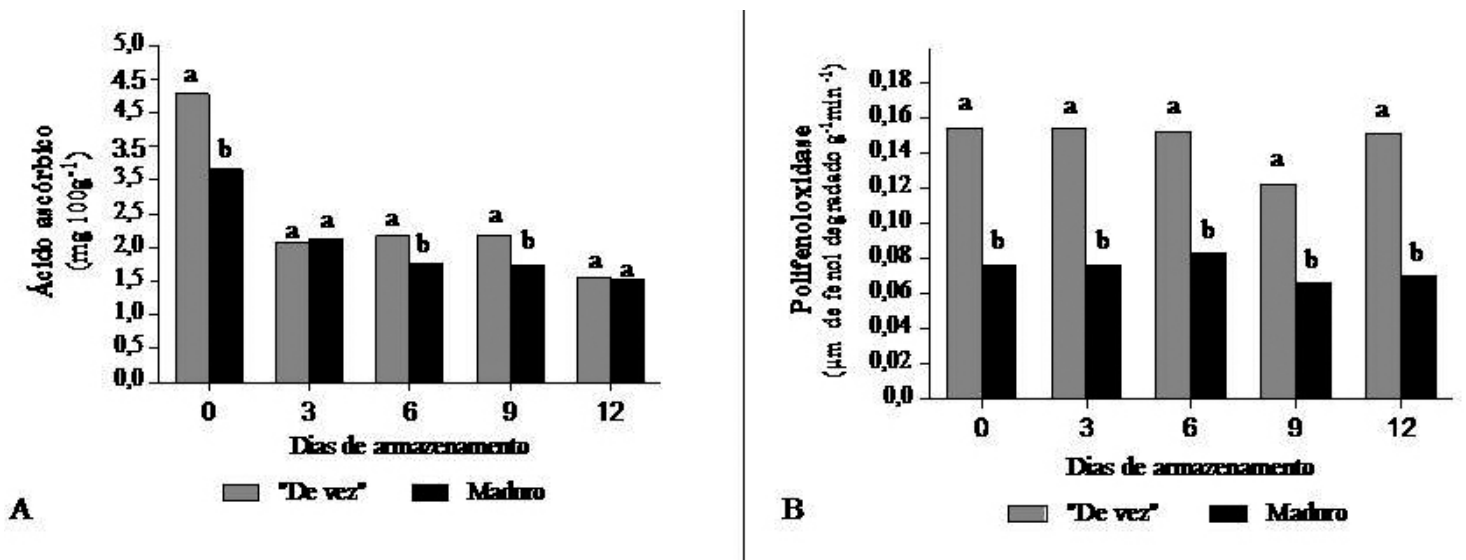

FIGURA 4- Teores de ácido ascórbico $\left(\mathrm{mg}^{\left.100 \mathrm{~g}^{-1}\right)}\right.$ (A) e atividade da polifenoloxidase ( $\mu$ mol de fenol consumido $\mathrm{g}^{-1} \mathrm{~min}^{-1}$ ) (B) de pêssegos 'Aurora-1' submetidos a processamento mínimo, em dois estádios de maturação, e armazenados a $3{ }^{\circ} \mathrm{C}$ e $65 \%$ UR. Médias seguidas de mesma letra dentro de cada período de armazenamento não diferem significativamente, pelo teste de Tukey $(\mathrm{P}<0,05)$. 

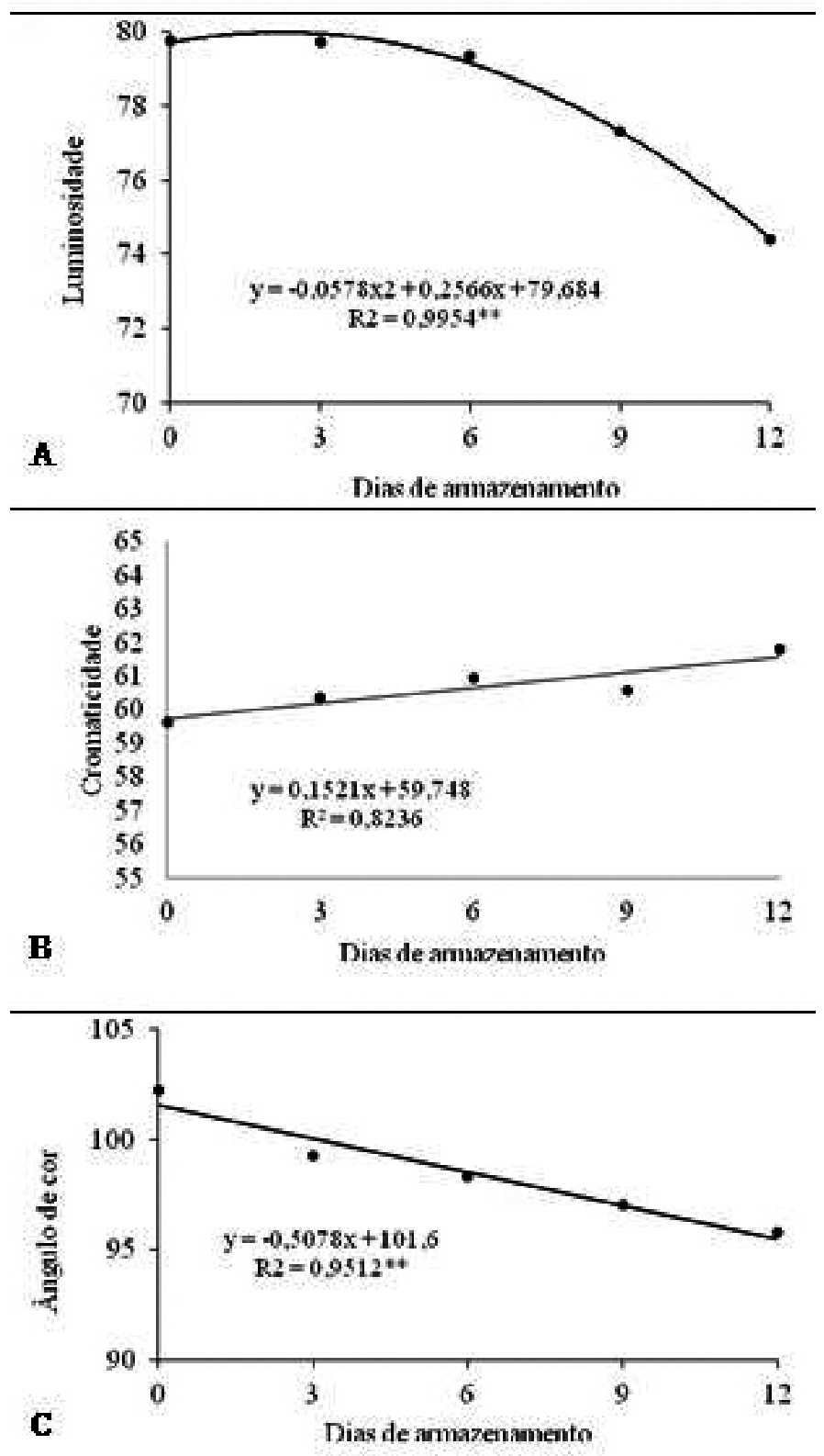

FIGURA 5 -Variação na luminosidade (A), cromaticidade (B) e ângulo de cor (C) de pêssegos 'Aurora-1' submetidos ao processamento mínimo, em dois estádios de maturação, e armazenados a $3{ }^{\circ} \mathrm{C}$ e $65 \%$ UR.

\section{CONCLUSÃO}

Pêssegos 'Aurora-1', colhidos no estádio de maturação "de vez", apresentaram melhor qualidade e maior duração de seus produtos minimamente processados.

\section{AGRADECIMENTOS}

À Fundação de Amparo à Pesquisa de São Paulo (FAPESP), pelo recurso fornecido (Proc. 07/54815-4) para o desenvolvimento desta pesquisa. 


\section{REFERÊNCIAS}

ALlain, C. C.; POON, L. S.; CHAN, C. S. G.; RICHMOND, W.; FU, P. C. Enzymatic determination of total serum cholesterol. Clinical Chemistry, Baltimore, v.120, p.470-475, 1974.

CHITARRA, M. I. F.; CHITARRA, A. B. Pós-Colheita de Frutas e Hortaliças: Fisiologia e manuseio. Lavras: Editora de Universidade Federal de Lavras, 785 p.2005.

COSETENG, M.Y.; LEE, C.Y. Changes in apple polyphenoloxidase and polyphenol concentrations in relation to degree of browning. Journal of Food Science, Chicago, v.52, n.4, p.985-989, 1987.

COUTO, S.R.M.; DERIVI, S.C.N.; MENDEZ, M.H.M. Utilização tecnológica de subprodutos da indústria de vegetais. aproveitamento de subprodutos de vegetais. Higiene Alimentar, São Paulo, v.18, p.12-22, 2004.

CUNHA, L. C.; DURIGAN, M.F.B.; MATTIUZ, B.H.; MARTINS, R.N.; DURIGAN, J.F. Caracterização da curva de maturação de pêssegos 'Aurora-1', na região de Jaboticabal-SP. Revista Brasileira de Fruticultura, Jaboticabal, v.29, n.3, p.661-665, 2007.

DUBOIS, M.; GILLEWS, K.A.; HAMILTON, J.K.; REBER, P.A.; SMITH, F. Colorimetric method for determination of sugar and related substances. Analytical Chemistry, Washington, v.8, n.3, p.350$6,1956$.

FERRER, A.; REMÓN, S.; NEGUERUELA, A.L.; ORIA, R. Changes during the ripening of the very late season Spanish peach cultivar 'Calanda' Feasibility of using CIELAB coordinates as maturity indices. Scientia Horticulturae, Amsterdam, v.105, n.4, p.435-446, 2005.

GORNY, J. R.; HESS-PIERCE, B.; CIFUENTES, R. A.; KADER, A. A. Quality changes in fresh-cut pear slice as affected by controlled atmospheres and preservatives. Postharvest Biology and Technology, Amsterdam, v.24, p.271-278, 2002

GORNY, J.R.; HESS-PIERCE, B.; KADER, A.A. Effects of fruit ripeness and storage temperature on the deterioration rate of fresh-cut peach and nectarine slices. Hortscience, Alexandria, v. 33, p.110-113, 1998.
INSTITUTO ADOLFO LUTZ. Métodos físico-químicos para análise de alimentos. 4.ed. São Paulo, 2008.

KASAT, G. F.; MATTIUZ, B.; OGASSAVARA, F. O.; BINACO, M. S.; MORGADO, C. M. A.; CUNHA, L. C. Injúrias mecânicas e seus efeitos em pêssegos 'Aurora-1'. Revista Brasileira de Fruticultura, Jaboticabal, v.29, n.2, p.318-322, 2007.

MATTIUZ, B.H.; DURIGAN, J.F.; ROSSI JÚNIOR, O. Processamento mínimo em goiabas 'Paluma' e 'Pedro Sato'. 2. Avaliação química, sensorial e microbiológica. Ciência e Tecnologia de Alimentos, Campinas, v. 23, n. 3, p. 409-413, 2003.

MATHIAS, C.; MAYER, N. A.; MATTIUZ, B. H.; PEREIRA, F. M. Efeito de porta-enxertos e espaçamentos entre plantas na qualidade de pêssegos 'Aurora'. Revista Brasileira de Fruticultura, Jaboticabal, v.30, n. 1, p. 165-170, 2008.

MILLER, G. L. Use of dinitrosalicylic acid reagent for determination of reducing sugar. Analytical Chemistry, Washington, v.31, n. 3, p. 426-428, 1959.

OLIVEIRA, M. A. de; CEREDA, M. P. Pós-colheita de pêssegos (Prunus persica (L.) Batsch) revestidos com filmes à base de amido como alternativa à cera comercial. Ciência e Tecnologia de Alimentos, Campinas, v.23, p.28-33, 2003.

REMORINI,D.; TAVARINI, S.; DEGL "INNOCENTI, E., LORETI, F.; MASSAI, R.; GUIDI, L. Effect of rootstocks and harvesting time on the nutritional quality of peel and flesh of peach fruits. Food Chemistry, Oxford, v.110, p. 361-367, 2008.

ROMBALDI, C.V.; SILVA, J.A.; PARUSSOLO, A.; LUCCHETTA, L.; ZANUZO, M.R.; GIRARDI, C.L.; CANTILLANO, R.F.F. Armazenamento de pêssegos (Prunus persica L.), cultivar Chiripá, em atmosfera controlada. Ciência Rural, Santa Maria, v.32, n.1, p.43-47, 2002.

TECCHIO, M.A.; BETIOL NETO, J.E.; BARBOSA, W.; SAN'ANA, M.L. Evolution and perspective of the temperature fruit crops in São Paulo state, Brazil. Revista Brasileira de Fruticultura, Jaboticabal, v. 33, n.1 - edição especial, p. 150-157. 2011. 